\title{
Qualidade fisiológica e sanitária de sementes de Cordia americana coletadas na planta e no solo
}

\section{Physiological and sanitary quality of Cordia americana seeds collected in plant and soil}

\author{
Clair Walker ${ }^{1}$, Ricardo Mezzomo ${ }^{2}$, Caciara Gonzatto Maciel ${ }^{3}$, Marlove Fátima Brião Muniz $^{4}$, Maristela Machado Araujo ${ }^{5}$
}

Resumo: A guajuvira é uma espécie florestal nativa amplamente distribuída no território brasileiro e possui demanda de pesquisas quanto à qualidade de suas sementes. Este trabalho teve como objetivos, avaliar a qualidade fisiológica e sanitária de sementes de guajuvira, coletadas na planta e após sua dispersão no solo em diferentes períodos. As variáveis analisadas foram: teor de água das sementes, matéria seca, germinação, vigor e sanidade de sementes. A qualidade sanitária foi determinada pela identificação dos microorganismos associados às sementes, dentre os quais foram identificados: Fusarium sp., Cladosporium sp., Alternaria sp., Colletotrichum sp., Aspergillus sp. e Penicillium sp. As sementes oriundas de frutos extraídos na planta atingiram valores superiores de germinação e vigor e a ocorrência de Fusarium sp. foi maior pois a associação do fungo pode ocorrer durante a maturação dos frutos.

Palavras-chave: coleta de sementes, guajuvira, patologia de sementes, sementes florestais

\begin{abstract}
The guajuvira is a native forest species widely spread in Brazil and has a demand for research on the quality of its seeds. This study aims to survey the physiological and sanitary quality of guajuvira seeds, collected in the plant and after its dispersion in the soil at different periods. The variables analyzed were: water content, dry mass, germination and vigor. The sanitary quality was determined by identification of microorganisms associated with the seeds, among them were identified Fusarium sp., Cladosporium sp., Alternaria sp., Colletotrichum sp., Aspergillus sp. and Penicillium sp. Seeds from fruits collected in the plant reached higher values of germination and vigor and the occurrence of Fusarium sp. was higher because the fungus association can occur during the fruits maturation.
\end{abstract}

Keywords: seed collection, guajuvira, seed pathology, forest seeds

${ }^{1}$ Universidade Federal de Santa Maria - Departamento de Defesa Fitossanitária; E-mail: clairwalker@gmail.com;

${ }^{2}$ Universidade Federal de Santa Maria - Departamento de Defesa Fitossanitária; E-mail: mezzomoricardo@ hotmail.com

${ }^{3}$ Universidade Federal de Santa Maria - Departamento de Defesa Fitossanitária; E-mail: caciaragonzatto@ gmail.com

${ }^{4}$ Universidade Federal de Santa Maria - Departamento de Defesa Fitossanitária; E-mail: marlovemuniz@yahoo.com.br

${ }^{5}$ Universidade Federal de Santa Maria - Departamento de Defesa Fitossanitária; E-mail: araujo.maristela@ gmail.com
} 


\section{INTRODUÇÃO}

Nas décadas de 50 a 80, não havia demanda por espécies florestais nativas e mesmo para algumas exóticas, no entanto, a preocupação com a produção de sementes nativas intensificou-se a partir dos anos 80, com o aumento da conscientização ambiental (PIÑA-RODRIGUES et al., 2007). Nas últimas décadas, tem sido visível a necessidade de conservação e recuperação da biodiversidade para não comprometer a sobrevivência das futuras gerações. Todavia, a grande diversidade de espécies acarreta a carência de informações técnicas sobre produção de sementes e mudas, o que consequentemente tem ocasionado um déficit na demanda de sementes para serem utilizadas em projetos de conservação e reflorestamento.

Dentre as espécies florestais, Cordia americana (L.) Gottschling \& J. S. Mill, popularmente conhecida como guajuvira, apresenta poucos de estudos nesse sentido. A guajuvira é considerada de alto valor comercial, indicada para construção civil, obras externas, cabos de ferramentas, no paisagismo em geral, assim como, para reflorestamento (CARVALHO, 2003).

A propagação da maioria das espécies florestais nativas ocorre por via sexuada. Atualmente, existe uma preocupação constante por parte dos produtores de sementes em relação à época ideal de colheita. Nesse sentido, são necessárias informações acerca da maturação fisiológica de sementes de cada espécie, bem como estudos e técnicas que venham contribuir para aumentar a qualidade fisiológica e sanitária das sementes.

A contaminação fúngica em sementes de essências florestais, especialmente, das plantas nativas, pode estar relacionada às características próprias dos frutos e do processo como as sementes são coletadas, beneficiadas e armazenadas. Normalmente, a colheita das sementes é realizada no solo, devido à dificuldade de retirada dos frutos em árvores de porte elevado, onde os frutos e sementes geralmente são colonizados por fungos diversos (FERREIRA 1989). Medeiros et al. (2007), citam que após o ponto de maturação fisiológica, as sementes que permanecem no campo ficam sujeitas às condições ambientais adversas, que as deterioram progressivamente.

A associação de microrganismos em sementes pode ocorrer durante o processo de maturação, causando prejuízos no decorrer do processo germinativo. A ocorrência de fungos dos gêneros Fusarium, Colletotrichum, Alternaria, Helminthosporium, dentre outros, conhecidos como "fungos de campo", é aumentada durante o período prolongado de permanência das sementes no campo após a maturidade, onde são expostas às condições de ambiente úmido e quente (MARCOS FILHO, 2005).

A produção, obtenção e manutenção de sementes com elevada qualidade assumem papel fundamental na preservação das espécies. Diante da escassez de informações sobre a tecnologia de sementes de Cordia americana, o objetivo da presente pesquisa foi verificar a qualidade fisiológica e sanitária de sementes extraídas da planta ou coletadas no solo em diferentes períodos.

\section{MATERIAL E MÉTODOS}

As sementes de guajuvira foram coletadas, no mês de dezembro de 2011, de três árvores matrizes (visualmente sadias e copa bem formada) plantadas em uma área situada na Fundação Estadual de Pesquisa Agropecuária (FEPAGRO), coordenadas geográficas de 29" 39' 45 de latitude Sul e 53" 55' 12 de longitude Oeste de Greenwich, localizada no município de Santa Maria, região fisiográfica da depressão central do Rio Grande do Sul. As análises de sementes foram realizadas no Laboratório de Pesquisa em Fitopatologia, pertencente ao Departamento de Defesa Fitossanitária, Centro de Ciências Rurais da Universidade Federal de Santa Maria.

$\mathrm{O}$ amadurecimento dos frutos foi verificado na primeira semana de dezembro, observado pela transição da cor amarelada para marrom-claro. Os mesmos foram coletados primeiramente no solo e após estendeu-se uma lona sob a copa das árvores e efetuou-se a coleta dos frutos extraídos da planta, procurando-se coletar na porção superior e inferior da copa nas quatro direções, com o auxílio de podão e escadas. Assim, os frutos da planta que caíram sob a lona foram coletados, evitando o contato com o solo. As coletas diretamente na planta e no solo foram efetuadas aos 52 e 55 dias após antese (DAA), correspondendo ao primeiro e segundo período de coleta (PC1 e PC2). As amostras dos frutos foram devidamente identificadas de acordo com o método (sementes coletadas na planta e sementes coletadas no solo) e período de coleta. Em seguida, as sementes foram acondicionadas em embalagens de plástico e encaminhadas ao laboratório. $\mathrm{O}$ beneficiamento foi realizado imediatamente após a coleta, por meio da retirada manual do cálice do fruto, sendo que após esse procedimento, as sementes permaneceram em ambiente de laboratório para a secagem até o dia seguinte, quando para a realização foram realizadas as análises.

O teor de água das sementes de guajuvira foi determinado pelo método da estufa a $105 \pm 3^{\circ} \mathrm{C}$, durante 24 horas (BRASIL, 2009), utilizando-se três subamostras de 25 sementes para cada período e método de coleta (sementes maduras coletadas na planta e sementes maduras coletadas no solo).

Os experimentos do teste de germinação e primeira contagem foram conduzidos com quatro repetições de 25 sementes para cada método e período de coleta. As sementes foram desinfestadas com uma solução aquosa de hipoclorito de sódio a $1 \%$ (v/v) e em seguida, por uma solução de álcool a $70 \%$ (v/v), ambos por 30 segundos e, após, lavadas em água destilada esterilizada. A semeadura foi em caixas "gerbox", utilizando-se como substrato areia peneirada $(\leq 2 \mathrm{~mm}$ de malha) e autoclavada por duas vezes $\left(1 \mathrm{~atm}\right.$ e $120^{\circ} \mathrm{C}$ por 60 minutos com intervalo de 24 horas). As caixas "gerbox" foram mantidas em câmara de germinação a $25 \pm 2^{\circ} \mathrm{C}$ e fotoperíodo de 12 horas. A contagem das sementes germinadas iniciou no décimo quinto dia (primeira contagem), após a instalação do teste, encerrando-se aos 35 dias. Na primeira contagem (PCG) foram avaliadas as plântulas normais e, aos 35 dias, plântulas normais, anormais, sementes duras e mortas (contabilizadas como sementes não germinadas - SNG). O critério adotado para formação de plântula normal foi a presença de todas as estruturas essenciais (raiz primária, hipocótilo e cotilédones), segundo a Regras de Análise de sementes (BRASIL, 2009).

A condutividade elétrica (CE) das sementes foi determinada pelo método massal para cada período e método de coleta, utilizando-se quatro repetições de 25 sementes. As sementes foram previamente pesadas em balança analítica com precisão de $0,001 \mathrm{~g}$ e, posteriormente acondicionadas em 
copos de plástico, contendo $50 \mathrm{~mL}$ de água destilada por unidade. Os recipientes foram mantidos por 24 horas em câmara de germinação com temperatura de $25^{\circ} \mathrm{C}$. Após o período realizou-se a leitura da condutividade elétrica na solução de embebição, utilizando-se um condutivímetro Quimis $^{\circledR}$, e os valores obtidos foram expressos em $\mu \mathrm{S} \mathrm{cm}^{-1} \mathrm{~g}^{-}$

Para a avaliação da qualidade sanitária foi utilizada para cada método e período de coleta uma amostra de 100 sementes, divididas em quatro repetições, com 25 sementes, distribuídas em caixas de plástico transparente ("gerbox"). As mesmas foram previamente desinfestadas com solução de hipoclorito de sódio a $1 \%$ (v/v) e solução de álcool a $70 \%$ (v/v), forradas com duas folhas de papel filtro esterilizadas e umedecidas com água destilada e esterilizada. A incubação foi realizada em câmara com temperatura controlada a $25 \pm 2$ ${ }^{\circ} \mathrm{C}$ e fotoperíodo de 12 horas. Após sete dias foram realizadas a quantificação e identificação dos fungos, com o auxílio de microscópios estereoscópico e óptico, e bibliografia especializada: Barnett \& Hunter (1999).

O delineamento experimental utilizado para as avaliações da qualidade fisiológica e sanitária das sementes foi inteiramente casualizado, bifatorial $2 \times 2$, perfazendo quatro tratamentos com quatro repetições, sendo que o fator " $A$ " referiu-se aos métodos de coleta (sementes coletadas na planta e sementes coletadas no solo) e o fator " $\mathrm{B}$ " referiu-se aos períodos de coleta (52 e 55 DAA). Os dados foram submetidos ao teste de normalidade de Shapiro-Wilk e homogeneidade de variância pelo teste de Bartlett. Devido a essas condições não ter sido atendidas, procedeu-se à transformação dos dados pela função arcoseno $(\mathrm{x} / 100)^{0,5}$. Foram realizadas análises de variância e, quando o valor de $\mathrm{F}$ foi significativo, as médias foram comparadas pelo teste de Tukey ao nível de 5\% de probabilidade de erro. As análises estatísticas foram realizadas com o auxílio do programa estatístico SISVAR (FERREIRA, 2009).

\section{RESULTADOS E DISCUSSÃO}

Em relação ao teor de água, massa fresca e seca das sementes, primeira contagem de germinação (PCG), plântulas normais, sementes não germinadas (SNG) e sanidade de sementes verificou-se que não houve interação significativa entre o método e período de coleta.

Quando analisado o método de coleta de sementes nos dois períodos, os dados referentes ao teor de água indicaram que as sementes coletadas no solo apresentaram menor teor de água (9,85\%), diferenciando-se estatisticamente das coletadas na planta. Carvalho \& Nakagawa (2000) relatam que a desidratação das sementes pode ser influenciada pelas condições climáticas, ocorrendo oscilações de acordo com a umidade relativa do ar. Essa redução do teor de água das sementes após a queda no solo pode estar relacionada ao tempo de exposição das sementes às condições climáticas, sendo que a partir desse período pode-se inferir que as sementes iniciariam o processo de desidratação e perda da viabilidade.

O teor de água de sementes de guajuvira, provenientes também da região central do Rio Grande do Sul, apresentaram semelhanças nas características fisiológicas nos diferentes lotes, sendo que Steirnagel et al. (2012) verificaram que as sementes atingiram $12,4 \%$ de teor de água.

A porcentagem de plântulas normais na primeira contagem de germinação (PCG) foi superior nas sementes coletadas aos 52 DAA (Tabela 1). Nesse período, foram contabilizadas $45 \%$ de plântulas normais germinadas, diferindo significativamente do número de plântulas germinadas aos 55 DAA (10\%). Em relação à porcentagem de plântulas normais, houve diferença significativa entre os períodos de coleta, sendo observados $55 \%$ e $20 \%$ de plântulas normais, respectivamente aos 52 e 55 DAA. No teste de germinação, constatou-se a presença de sementes não germinadas (SNG), incluídas na categoria das sementes duras e mortas. Verificou-se que $70 \%$ das sementes não germinaram aos 55 DAA, diferindo significativamente das sementes coletadas aos 52 DAA (25\%) (Tabela 1). Dessa maneira, observa-se maior qualidade fisiológica das sementes quando coletadas logo após sua maturação, ou seja, aos 52 DAA.

Tabela 1. Condutividade elétrica (CE), primeira contagem de germinação (PCG), plântulas normais, plântulas anormais e sementes não germinadas (SNG) de sementes de Cordia americana obtidos no primeiro (PC1) e segundo (PC2) períodos de coleta

\begin{tabular}{cccccc}
\hline & \multicolumn{1}{c}{ CE } & & & & \\
Período & $\left(\mu \mathrm{Sm}^{-1} \mathrm{~g}^{-1}\right)$ & PCG $(\%)$ & Normais $(\%)$ & Anormais $(\%)$ & SNG $(\%)$ \\
\hline PC1 (52 DAA) & $39,88 \mathrm{a}^{*}$ & $45,0 \mathrm{a}$ & $55,0 \mathrm{a}$ & $20,0 \mathrm{a}$ & $25,0 \mathrm{a}$ \\
PC2 (55 DAA) & $43,99 \mathrm{a}$ & $10,0 \mathrm{~b}$ & $20,0 \mathrm{~b}$ & $10,0 \mathrm{a}$ & $70,0 \mathrm{~b}$ \\
\hline Média & 41,93 & 27,5 & 37,5 & 15,25 & 47,25 \\
\hline CV $(\%)$ & 11,88 & 42,39 & 23,84 & 46,97 & 16,23 \\
\hline
\end{tabular}

*Médias seguidas pela mesma letra, na coluna, não diferem entre si pelo Teste de Tukey a 5\% de significância. C.V.(\%) = coeficiente de variação. DAA = Dias após antese

Não houve diferença estatística significativa para as variáveis CE, PCG, plântulas normais e plântulas anormais para os períodos de coleta de sementes. Para a variável SNG foi observada uma maior porcentagem no método de coleta no solo $(57 \%)$, diferindo significativamente com o método de coleta na planta, que apresentou 37,5\% de sementes não germinadas. Pode-se inferir que o maior número de SNG das sementes coletadas no solo se deve ao fato da maior deterioração das mesmas quando estas permanecem por maior período expostas às condições do ambiente. Araujo et al. (2009) também verificaram que, em fava d'anta (Dimorphandra mollis Benth.), as sementes provenientes de frutos coletados no solo deram origem a uma maior porcentagem de sementes mortas. Os autores sugerem que a 
ação dos fungos afeta a germinação e o desenvolvimento das plântulas, pois a incidência de fungos em sementes coletadas no solo foi superior às coletadas na planta.

$\mathrm{Na}$ avaliação sanitária das sementes de Cordia americana foram detectados seis gêneros fúngicos que foram identificados associados às sementes coletadas na planta e no solo, nos períodos de coleta PC1 e PC2, dentre eles estão: Fusarium sp., Cladosporium sp., Alternaria sp., Colletotrichum sp., Penicillium sp. e Aspergillus sp. Araujo et al. (2009) verificaram a ocorrência de Fusarium sp., Alternaria sp., Aspergillus sp., Cladosporium sp., Colletotrichum sp., Helminthosporium sp., Nigrospora sp., Penicillium sp., Phoma sp. e Phomopsis sp. associados às sementes de fava d'anta coletados na planta e no solo. Os autores relatam que independente da forma de coleta das sementes, os fungos Cladosporium sp. e Fusarium sp. foram os que mais ocorreram nas sementes analisadas.

Dentre os fungos identificados, apenas Fusarium sp. diferiu significativamente entre as sementes coletadas na planta $(40,5 \%)$ e no solo $(14,5 \%)$. A maior incidência de Fusarium sp. em sementes coletadas na planta pode ser explicada por Machado et al. (2000), onde os autores relatam que as associações com fungos do gênero Fusarium podem ser observadas durante a maturação dos frutos. Menten e Bueno (1987) afirmam que a infecção por Fusarium spp. pode ocorrer através do pedúnculo de flores, frutos e da semente, ou pela superfície íntegra da semente. Wetzel (1987) considera este patógeno um fungo de campo, ou seja, pode infectar as sementes no período de crescimento e maturação.

As flutuações de temperatura, umidade relativa, orvalho, chuva, entre outros fatores podem favorecer ou não o desenvolvimento de fungos de campo em sementes, após sua queda no solo (VILLELA; PERES, 2004). Wetzel (1987) verificou que o desenvolvimento dos fungos de campo requer alta umidade. Dessa maneira, pode-se inferir que as sementes de guajuvira coletadas no solo apresentaram baixa umidade $(9,85 \%)$, conforme dados apresentados anteriormente, desfavorecendo o desenvolvimento de Fusarium sp.

\section{CONCLUSÕES}

As sementes de Cordia americana quando coletadas diretamente na planta aos 52 dias após antese apresentam qualidade fisiológica superior, após sua dispersão no solo, as mesmas acentuam seu processo de desidratação com consequente perda da viabilidade.

Os fungos Fusarium sp., Cladosporium sp., Alternaria sp., Colletotrichum sp. e Penicillium sp. estão associados às sementes coletadas na planta e no solo.

A maior incidência de Fusarium sp. é em sementes coletadas na planta e está, provavelmente, associada a contaminação durante a fertilização e maturação fisiológica das sementes.

\section{REFERÊNCIAS BIBLIOGRÁFICAS}

ARAUJO, A. V.; SALES, N. L. P.; FERREIRA, I. C. P. V.; BRANDÃO JUNIOR, D.; MARTINS, E. R. Germinação, vigor e sanidade de sementes de fava d'anta (Dimorphandra mollis Benth.) obtidas de frutos coletados no solo e na planta. Revista Brasileira de Plantas Medicinais, v. 11, n. 2, p. 170-175, 2009.
BARNETT, H. L.; HUNTER, B. B. Illustred genera of imperfect fungi. 3. ed. Minnesota: Burgess Publishing Company, 1999. $241 \mathrm{p}$.

BRASIL. Ministério da Agricultura, Pecuária e Abastecimento. Regras para análise de sementes. Brasília, DF, 2009. 399 p.

CARVALHO, P. E. R. Espécies arbóreas brasileiras. Brasília: EMBRAPA Informação Tecnológica. Colombo, PR: EMBRAPA Florestas, v. 1, 2003. 1039 p.

CARVALHO, N. M.; NAKAGAWA, J. Sementes: ciência, tecnologia e produção.

FUNEP. Jaboticabal, 2000. 588 p.

FERREIRA, D. F. Estatística básica. Lavras: UFLA, 2. ed. Ampliada e revisada, 2009. 664p.

FERREIRA, F. A. Patologia florestal: principais doenças florestais no Brasil. Viçosa: Sociedade de Investigações Florestais, 1989. 570p.

MACHADO, J. C. Tratamento de sementes no controle de doenças. Lavras: LAPS/UFLA/FAEPE, 2000. 138p.

MARCOS FILHO, J. Fisiologia de sementes de plantas cultivadas. Piracicaba: Fealq, 2005. 495 p.

MEDEIROS, C. S.; CHODOR, J.; BULGACOV, A. Coleta de sementes em árvores altas [recurso eletrônico] Dados eletrônicos. - Colombo: Embrapa Florestas, 2007.

MENTEN, J. O. M.; BUENO, J. T. Transmissão de patógenos pelas sementes. In: SOAVE, J.; WETZEL, M. M. V. da S. (Ed.). Patologia de sementes. Campinas: Fundação Cargill, 1987. p. 164-191.

PIÑA-RODRIGUES, F. C. M. et al. Estado da arte da produção de sementes de espécies florestais na Mata Atlântica. In: PIÑA-RODRIGUES, F. C. M. et al. Parâmetros técnicos para produção de sementes florestais. Seropédica: EDUR/UFRRJ, 2007. cap. 1, p. 11-33.

STEIRNAGEL, E. L. et al. Avaliação da germinação de sementes de Cordia americana (L.) Gottshling \& J.E.Mill. em diferentes substratos, II Congresso Brasileiro de Reflorestamento Ambiental., Guarapari: Sesc. CD-Rom, 2012.

VILLELA, F. A.; PERES, W. B. Coleta, Beneficiamento e Armazenamento. In: FERREIRA, A. G.; BORGHETTI, F. (Ed.). Germinação: do básico ao aplicado. Porto Alegre: Artmed, 2004. cap. 17, p. 266-281.

WETZEL, M. M. V. S. Fungos de armazenamento. In: SOAVE, J.; WETZEL, M. M. V. S. (Ed.) Patologia de sementes. Campinas: Fundação Cargill, 1987. p. 260275. 